Portland State University

PDXScholar

Summer 8-29-2019

\title{
Annual and Seasonal Variation in Hydrologic Performance of Ecoroofs of Multiple Depths, Portland, OR
}

Ashley Michelle Baker

Portland State University

Follow this and additional works at: https://pdxscholar.library.pdx.edu/open_access_etds

Part of the Hydrology Commons, and the Urban, Community and Regional Planning Commons Let us know how access to this document benefits you.

\section{Recommended Citation}

Baker, Ashley Michelle, "Annual and Seasonal Variation in Hydrologic Performance of Ecoroofs of Multiple Depths, Portland, OR" (2019). Dissertations and Theses. Paper 5274.

https://doi.org/10.15760/etd.7147

This Thesis is brought to you for free and open access. It has been accepted for inclusion in Dissertations and Theses by an authorized administrator of PDXScholar. Please contact us if we can make this document more accessible: pdxscholar@pdx.edu. 
Annual and Seasonal Variation in Hydrologic Performance of Ecoroofs of Multiple Depths, Portland, OR

by

Ashley M. Baker

A thesis submitted in partial fulfillment of the requirements for the degree of

\author{
Master of Science \\ in \\ Geography
}

\begin{abstract}
Thesis Committee:
Heejun Chang, Chair Olyssa Starry

Martin Lafrenz
\end{abstract}

Portland State University

2019 


\section{Abstract}

It is essential that cities adopt new approaches to stormwater management in the face of changing precipitation regime. In some locations, ecoroofs have been incorporated into city plans as a stormwater control measure, and thus their realworld performance under current conditions can assist with adequate planning. In this study rainfall retention data collected during a three year period, between 2014-2017, is analyzed for 75mm and 125mm ecoroof plots in Portland, Oregon, USA. There is no difference in annual rainfall retention performance between the shallower and deeper plots. However, the $36 \%$ mean annual retention of the ecoroof plots is a significant improvement over the conventional rooftop. The two ecoroof plots exhibit similar performance, despite their difference in substrate depth, under high, medium, or low precipitation events, as defined by local meteorological conditions. Additionally, the $125 \mathrm{~mm}$ ecoroof plot exhibits significantly greater performance during low intensity versus high intensity storms. The range of rainfall retention for the $125 \mathrm{~mm}$ ecoroof under a precipitation event of low intensity ranges from $32 \%$ to $100 \%$, with an average retention of $81 \%$, while the high intensity events see a mean retention of $26 \%$. The general trend of ecoroof behavior indicates that rainfall retention capacity shows a negative correlation ( $r h o=-0.37, p=0.00$ ) with increasing precipitation intensity for the $125 \mathrm{~mm}$ plot. Overall, these findings indicate that extensive ecoroofs of shallower depths are capable of retaining a substantial amount of stormwater. However, their performance is at its worst during the high intensity 
events that have the potential to overload sewer systems. Further investigation into rainfall retention capabilities of these ecoroofs is warranted to provide more information about design principles, such as vegetation type and diversity, which could also be impactful. 


\section{Acknowledgements}

I would like to acknowledge the support from my friends, family, and associated community members. This project would not have been possible without the input and guidance of the faculty at Portland State University, specifically my committee members and members of the Geography Department, as well as my peers in the water lab. I would like to extend a special thank you to the City of Portland and Bureau of Environmental Services for providing data and sharing ongoing knowledge of the site. 


\section{Table of Contents}

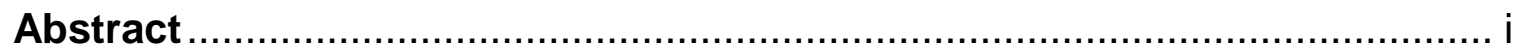

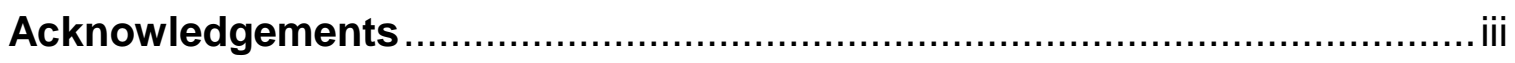

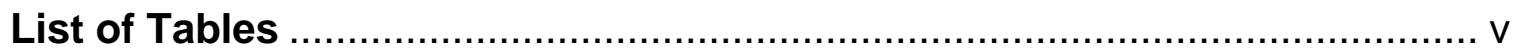

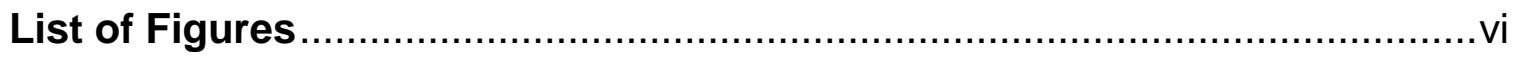

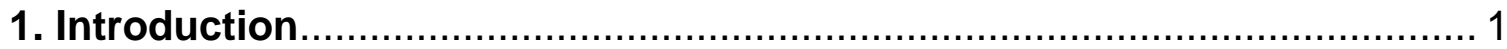

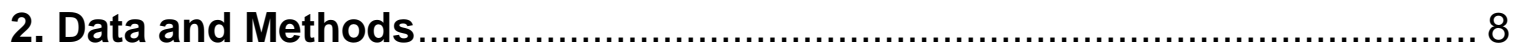

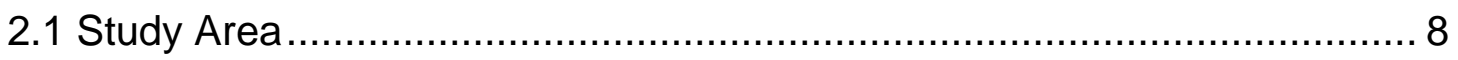

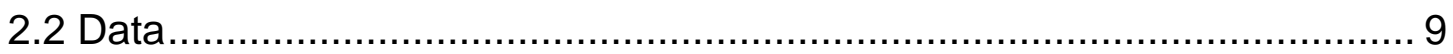

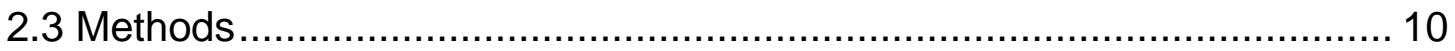

2.3.1 Data Preparation …................................................... 10

2.3.2 Assumptions..................................................................... 11

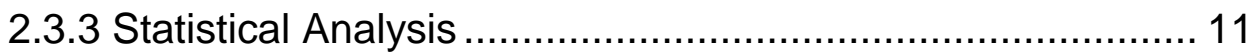

2.3.3.1 Retention by depth ............................................ 13

2.3.3.2 Retention by depth and intensity ........................... 13

2.3.3.3 Retention by depth and grouped intensity ............. 14

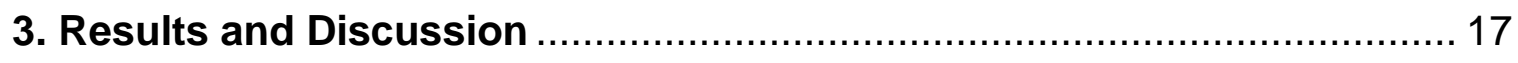

3.1 Annual Rainfall Runoff Capacity .................................................... 17

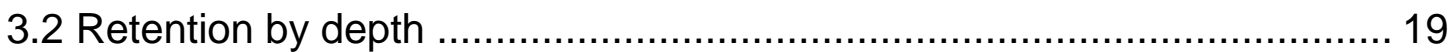

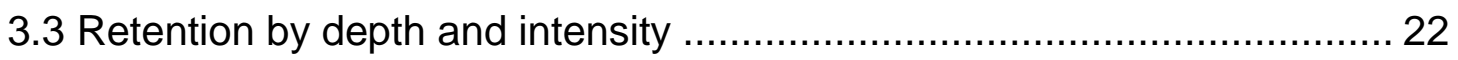

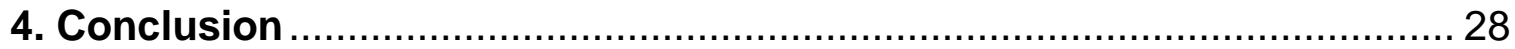

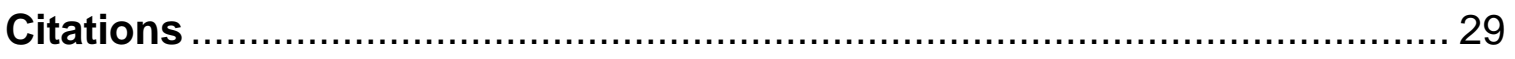

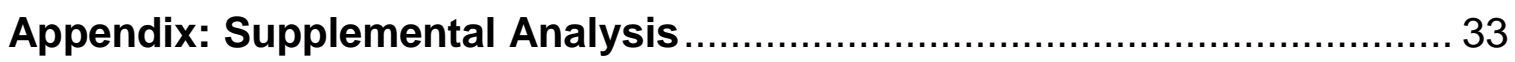




\section{List of Tables}

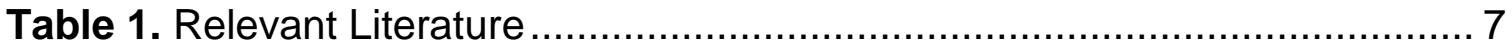

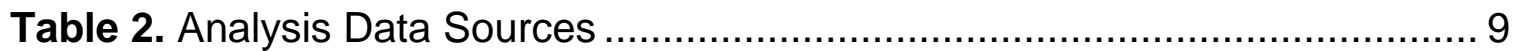

Table 3. Event characteristics by water year .............................................. 18

Table 4. Annual Retention................................................................... 18

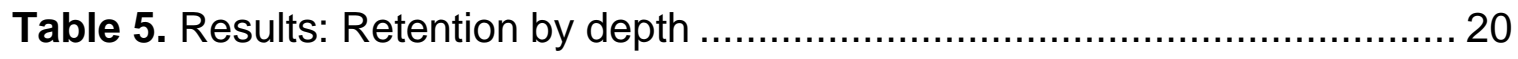

Table 6. Results: Generalized Linear Model all plots ..................................... 24

Table 7. Results: Retention by depth and grouped intensity ........................... 25

Table 8. Results: Retention by grouped intensity ......................................... 26 


\section{List of Figures}

Figure 1: Ecoroof Conceptual Diagram ………....................................... 5

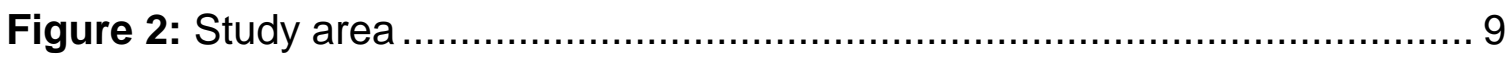

Figure 3: Scatterplot retention and intensity ……..................................... 22

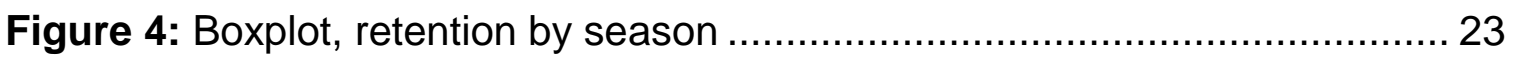

Figure 5: Boxplot retention by intensity and depth ...................................... 24 


\section{Introduction}

With changing climate characteristics and increasing impervious surface area due to development, stormwater runoff is anticipated to become a greater concern in urbanizing areas. These changes have many implications regarding future stormwater management as observed shifts in stormwater runoff characteristics such as volume and quality (Redfern et al. 2016) could affect the potential for urban flooding by overloading sewer systems (Rosenzweig et al. 2018). Stormwater green infrastructure (SGI) is becoming a more commonly adopted stormwater management approach during planning (McPhillips and Matsler 2018), an effort to moderate existing water issues and plan for future system stress.

One specific design of SGI, which is increasingly popular, both in application (van der Meulen 2019) and literature, is the ecoroof. This architectural feature is engineered to mimic a natural vegetated system, practical for exposed urban rooftops (BES 2009). Ecoroofs are an SGI facility that may be installed either during the process of new construction or retrofitted to existing roofs, taking advantage of otherwise barren urban space. They consist of multiple layers, all designed to systematically increase the roof's functionality through a combination of man-made and natural materials, ultimately providing an array of socio-eco-hydrological benefits (van der Meulen 2019). Social benefits include increased value over the life of the roof and aesthetic value of the property (Berto et al. 2018), as well as health benefits associated with the thermal regulating 
capacity of the roofs (Nardini et al. 2012) and improved air quality (Tan et al. 2017). Ecological benefits are known to be great, with many ecoroof designs incorporating vegetation that may sustain urban insects and small animals (BES 2010). Hydrological benefits (Figure 1) include a reduction in stormwater runoff and increased evapotranspiration (Mentens et al. 2005, Starry et al. 2016, DeVille et al. 2018), which lessen the stress on sewer systems (Berto et al. 2018). As rooftops account for substantial urban impervious surface area, sometimes up to $40-50 \%$ (Mentens et al. 2005, Zhang and Guo 2013), the potential for urban space to benefit from ecoroofs as an alternative is large.

The ability of ecoroofs to serve as a control measure for the reduction of stormwater runoff is well documented (Table 1) as the facilities are designed to capture incoming precipitation, reducing peak-flow and stormwater volume (Palla et al. 2010). Recent literature has explored the ability of ecoroofs to mitigate flooding, such as the ability to reduce flash-flood area (Liu et al. 2017). Other studies suggest that under the Pacific Northwest climate regime ecoroofs exhibit the potential to retain anywhere from $12 \%$ to $17 \%$ (Spolek 2008 ) or $23.2 \%$ to 32.9\% (Schultz et al. 2018) of precipitation annually, depending on the roof. Previous studies show that rainfall retention capacity $(R R C)$ of ecoroofs may vary by season in temperate climates, sometimes much higher in the summer season than in the winter (DeVille et al. 2018), with reported average seasonal values ranging from $20 \%$ to $48 \%$ over multiple locations (Mentens et al. 2006), and $12 \%$ to $42 \%$ in Portland, Oregon, USA (Spolek 2008). It is also common for the reported runoff reduction per event to have a broad range, such as the $6.4 \%$ to 
$100 \%$ reported by Cipolla et al. (2016). This variation is mostly attributed to differences in the volumetric water content of the soil between precipitation events, as well as differences in seasonal evapotranspiration (Hill et al. 2017).

Literature is indicating that there is a significant geographic dependency on the ability of an extensive ecoroof to retain incoming precipitation. Studies of retention performance over a range of climates, such as those performed by Talebi et al. (2019) and Viola et al. (2017) find that performance variability can be drastic between locations. Due to the complexity of variables driving rainfall retention capacity (RRC), such as precipitation event characteristics (Stovin et al. 2010), temporal components (Bouzouidja et al. 2018, De-Ville et al. 2018) and vegetation (Szota et al. 2017), most authors agree that the RRC values should not be extrapolated to other climates, indicating that location-specific studies are necessary (Burszta-Adamiak et al. 2019, Viola et al. 2017). Furthermore, Akther et al. 2018 found statistically significant differences in ecoroof performance by different climate classifications. With the influence of climate as one of the driving factors of ecoroof performance, local meteorological conditions must be considered with near equal importance to design principles.

Due to the relatively new impetus toward incorporating ecoroofs in city plans, a large proportion of recent literature focuses on the roof design characteristics that provide the most functionality. The design determines whether the roof is intensive or extensive, a designation related to substrate depth, substrate composition, vegetation, as well as the maintenance requirements (Palla et al. 2010, Soulis et al. 2017). As extensive roofs are 
thinner, at $<150 \mathrm{~mm}$ of substrate, they tend to be a preferred choice for builders with their lighter and cheaper installation (Soulis et al. 2017, Feitosa \& Wilkinson 2016) and lower maintenance requirements. Thus, understanding the relationship between substrate depth and RRC of ecoroofs is necessary to ensure that locally adopted standards are being met by newly installed ecoroofs. Studies have indicated that substrate depth is one of the most important design features of an ecoroof in determining its ability to retain stormwater, even more so than the slope of the roof or the vegetation type (Liu et al. 2019). It has also been established that antecedent dry weather periods (ADWPs) are pivotal in predicting green roof performance (Burszta-Adamiak et al. 2019, Schultz et al. 2018). As the ADWPs affect the inter-event recovery of storage capacity and influence changes in hydraulic conductivity (Feitosa \& Wilkinson 2016), the link between precipitation event characteristics and climate on the ability of substrate to retain water on an individual storm basis becomes more obvious. This again stresses the need for geographically specific determination of ideal substrate depth, as these characteristics must be accounted for.

As the compounding impacts of urbanization result in incidents such as overloaded greywater systems during storms (Liu et al. 2017), they require planned remediation and proactive controls. Cities such as Portland, OR are confronting them directly in city plans. An example of this is Portland's Central City 2035 plan, passed in 2018, which requires large new construction projects within the plan boundaries to incorporate, at minimum, an extensive ecoroof (City of Portland 2018). Understanding the relationship between substrate depth and 
$\mathrm{RRC}$ of ecoroofs is necessary to ensure that adopted standards are being met by newly installed ecoroofs. With cost also being a significant consideration in the benefit of ecoroof installation (Thuring \& Grant 2015), the determination of a minimum ecoroof depth capable of providing the intended stormwater control benefits must occur, securing both functionality and feasibility.

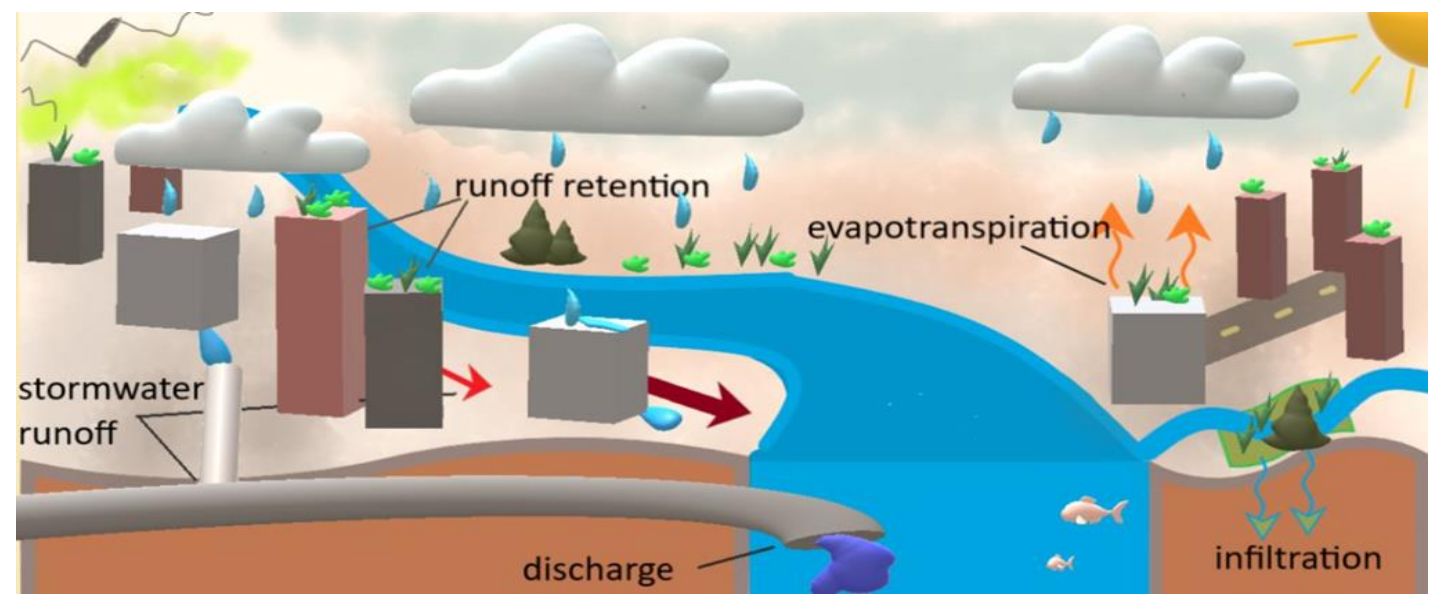

Figure 1: Model of ecoroof as a stormwater control measure in an urban setting

To increase practical knowledge surrounding the potential for functional application of ecoroofs in urban environments, their performance over time and space must undergo continuous study. Prior to passing the Central City 2035 requirements promoted the installation of ecoroofs both privately and publicly 
through a 2008-2012 incentive program (BES. nd), resulting in a higher concentration of facilities. As the city continues to engage with designs intended to promote future climate resilience, they have been monitoring select ecoroof facilities for performance. This is crucial in local stormwater management, as Portland is projected to see a combination of higher intensity precipitation events (Cooley \& Chang 2017), as well as higher volume of precipitation in the winter months (Rupp et al. 2017). Combined with a steady population growth (Oregon Metro. 2016) and associated development and increased impervious surfaces, this stresses the need for localized longer-term studies focused on SGI approaches. This research extends and expands on previous work by Shultz et al. (2018), in that it identifies behavior under a successive multi-year period. In turn, this study may increase recognition that ecoroofs remain a viable option for supporting hydrological system health in urbanized environments. For these reasons, this project proposes to answer the following questions:

1. What are the annual stormwater retention capacities of each ecoroof section?

2. Does a deeper $(125 \mathrm{~mm})$ or shallower $(75 \mathrm{~mm})$ ecoroof substrate provide better annual stormwater runoff reduction performance?

3. Does either the $125 \mathrm{~mm}$ or $75 \mathrm{~mm}$ ecoroof provide significantly better rainfall retention capacity under a range of precipitation intensities? 
Table 1: Relevant literature that reports rainfall retention values for similar extensive ecoroofs under a range of climates and scenarios

\begin{tabular}{|c|c|c|c|c|c|c|}
\hline Authors & Date & $\begin{array}{l}\text { Study } \\
\text { Area }\end{array}$ & Methodology & Roof Depth & Duration & Retention \\
\hline $\begin{array}{l}\text { Bouzouidja } \\
\text { et al. }\end{array}$ & 2018 & laboratory & Laboratory & $140 \mathrm{~mm}$ & - & $73 \%+/-10$ \\
\hline $\begin{array}{l}\text { Burszta- } \\
\text { Adamiak et } \\
\text { al. }\end{array}$ & 2018 & Poland & empirical & $100 \mathrm{~mm}$ & 5 year & $81.20 \%$ \\
\hline Hill et al. & 2012 & $\begin{array}{l}\text { Canada, } \\
\text { Toronto }\end{array}$ & empirical & $100 \mathrm{~mm}-150 \mathrm{~mm}$ & Summer & $70 \%$ \\
\hline Liu et al. & 2019 & China & $\begin{array}{l}\text { empirical } \\
\text { /simulation }\end{array}$ & $50 \mathrm{~mm}-150 \mathrm{~mm}$ & - & $25.4-28.9 \%$ \\
\hline Schultz et al. & 2018 & USA, Portland & Empirical & $75 \mathrm{~mm}, 125 \mathrm{~mm}$ & 1 year & $23.2 \%, 32.9 \%$ \\
\hline $\begin{array}{l}\text { Shafique et } \\
\text { al. }\end{array}$ & 2018 & Korea, Seoul & empirical & $30 \mathrm{~mm}$ & 3 days-June & $10 \%-60 \%$ \\
\hline $\begin{array}{l}\text { Spolek, } \\
\text { Graig }\end{array}$ & 2008 & USA, Portland & empirical & $150 \mathrm{~mm}$ & 3 years & $25 \%$ \\
\hline Talebi et al. & 2019 & $\begin{array}{l}\text { Canada, } \\
\text { various }\end{array}$ & model & $80 \mathrm{~mm}-220 \mathrm{~mm}$ & $\begin{array}{l}\text { March- Oct, } 7 \\
\text { years }\end{array}$ & $17 \%-50 \%$ \\
\hline Viola et al. & 2017 & Global & model & $90 \mathrm{~mm}$ & 100 years & $48 \%-52.8 \%$ \\
\hline
\end{tabular}




\section{Data and Methods}

\subsection{Study Area}

The ecoroof referenced in this study is located within the city of Portland, OR. The city is relatively large at about $375 \mathrm{~km}^{2}$ and contains 653,000 residents (US Census 2018). It has a Csb climate designation according to Köppen classification, a Mediterranean type regime characterized by drier summers and wetter winter months. The average temperature is mild for years 1981-2010, at $12.45^{\circ} \mathrm{C}$ and precipitation averages $913.89 \mathrm{~mm}$ annually, with $667.77 \mathrm{~mm}$ of that occurring between October and March (U.S.climatedata 2019).

The greater Portland area has been subject to many stormwater concerns, with reduction in combined sewer overflows a noted priority in management (BES 2016). The city also aims to reduce pluvial flooding, which causes damage through events such as basement sewer backups (BES 2016, Michelson and Chang 2019). Not all stormwater is treated before discharging into the Willamette River, which transects the more urbanized city center, influencing stormwater management requirements as well.

The roof was constructed in 2013 , containing $3,441 \mathrm{~m}^{2}$ of vegetated surface. It has three segments, the first consisting of a control section made of traditional roofing design, a second which has a depth of $75 \mathrm{~mm}$, and a third which has $125 \mathrm{~mm}$ substrate. All three of these segments have been recorded and are available for this purpose of this analysis. 


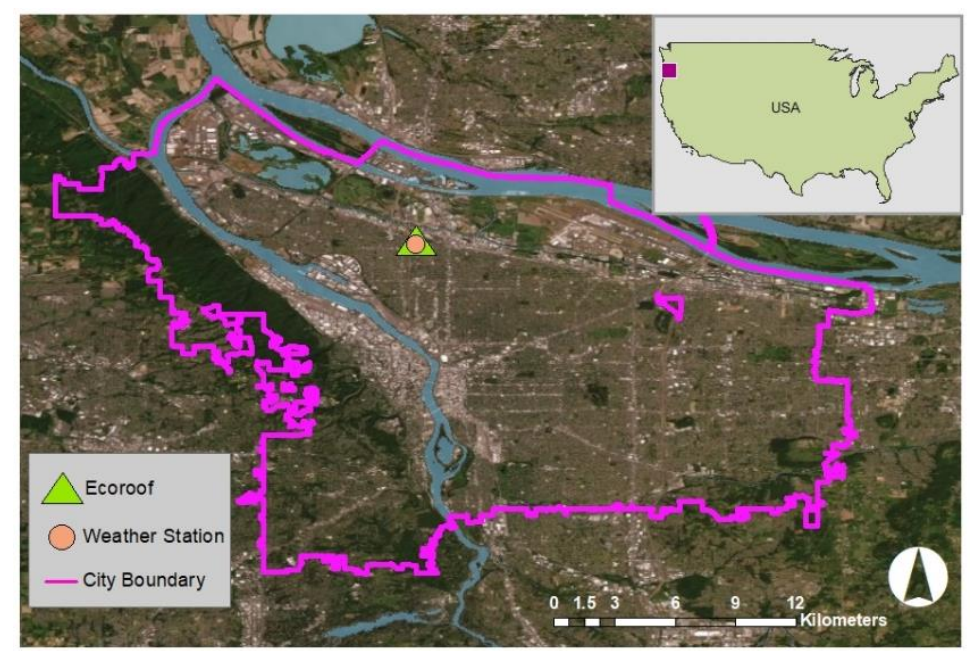

Figure 2: Ecoroof study site located in Portland, OR, USA

\subsection{Data}

Table 2. Hydroclimate data used in the current study

\begin{tabular}{llll}
\hline Variable & Source & Resolution & Location \\
\hline Precipitation & HYDRA & 1 hour & $49.5956,-$ \\
& Station & & 122.6794 \\
Outflow & 220 & & \\
& BES & 5 minute & $49.5956,-$ \\
& & & 122.6794 \\
\hline
\end{tabular}

Data has been collected by the City of Portland at the Walmart ecoroof in Portland, OR (Table 2). The data spans a period from October 1, 2014 to September 30, 2017. The Walmart ecoroof provided flow data using Plasti-fab extra-large 60-degree trapezoidal flumes with Hack US9001 Down-looking ultrasonic depth sensors, recorded every five minutes from the section outlets draining both the $125 \mathrm{~mm}$ and $75 \mathrm{~mm}$ ecoroof sections. This same collection 
process was repeated for the larger traditional roof section, which is to serve as the experimental control. Hourly precipitation data was derived from the USGS HYDRA network (2018), with hourly precipitation data collected from on-site rain gages located atop the Walmart roof.

\subsection{Methods}

\subsubsection{Data Preparation}

Ecoroof outflow values for the conventional, $75 \mathrm{~mm}$, and $125 \mathrm{~mm}$ plots at the Walmart location were aggregated to an hourly timescale spanning the October 1, 2014 to September 30, 2017 study period. The discharge and precipitation data were converted to $\mathrm{mm}$, accounting for differences in plot area. Precipitation events were defined as any time period where there is $>2 \mathrm{~mm}$ of precipitation following an ADWP of at least 12 hours (Buffman et al. 2017). This is more substantial than the 6 hour ADWP used to distinguish between precipitation events in other literature (Stovin et al. 2013, Burszsta-Admiak et al. 2018, Palla et al. 2018). For the purpose of this study, the longer ADWP was used as the distinguishing time period, a means to account for an overall gap in practical knowledge regarding the actual duration of ecoroof discharge following a precipitation event in this climate. As the intention of this study is to observe and assess real-world behavior, it was prioritized that the behavior of individual events be captured in addition to establishing event independence. The longer ADWP also ensures that the substrate has adequate time to recover storage capacity in between the events, assuming the different depths might require 
varied dry periods to accomplish this. However, under the climate regime of this locality, a longer ADWP means that there is a substantial range in precipitation event length, spanning from only a few hours to multiple days.

\subsubsection{Assumptions}

Due to the number of potentially impactful factors on ecoroof performance, certain assumptions had to be made in order to complete this comparative analysis. We assumed that all the ecoroof plots had identical design characteristics, varying only in their relative substrate depth. The substrate used for both plots was an industry standard mixture of pumice, sandy loam soil, and composted organic materials. However, it is possible that exact characteristics could have changed over time. Weathering, the addition of organic material (DeVille et al. 2018), and other processes could indicate that the plots are no longer identical to their design specifications (Bouzouidja et al. 2018). As the precipitation gauge was located on the conventional roof section, the climatic and meteorological conditions were assumed to be identical. This eliminates the need to incorporate other possible contributing factors of RRC, such as conditions impacting the potential evapotranspiration values of the rooftops which might vary over city area.

\subsubsection{Statistical Analysis}

All data preparation and statistical analysis were performed in the program $R$ version 3.5.1, using packages such as lubridate (Grolemund \& Wickham 
2011), dplyr (Wickham et al. 2018), and Ifstat (Gauster 2016) to clean, analyze, and visualize data.

After precipitation events and their corresponding outflow were determined, the proportion of discharge to precipitation (runoff ratio) was calculated. We subtracted runoff ratio from 1 and multiply by 100 to derive eventlevel RRC (Eq. 1), where $Q=$ hourly event discharge and $P=$ hourly event precipitation.

$$
R R C=\left(1-\left(\frac{Q}{P}\right)\right) * 100
$$

These event-level values were then used to compare behavior by plot substrate depth and year. Event intensity was calculated as the total volume of precipitation divided by the length of precipitation in hours. This value is included because it adds context to each individual storm scenario, which would be lost if the length of precipitation was not considered. However, since one representative observation is used to represent each storm, the peak discharge is not calculated.

Data points indicative of outliers, often falling outside of the Cook's Distance, are not removed from the final dataset unless necessary to improve model fit as indicated by R GLM model plots, as each event and its corresponding RRC have been visually verified. This methodology is used under 
the assumption that any extreme runoff or precipitation behavior results from practical scenarios, and as such is valid in determining real-world behavior.

\subsubsection{Retention by depth}

Storm event data from each ecoroof plot as well as the conventional rooftop were compared to determine the effect of depth on RRC. Because the data are not normally distributed even after the application of transformations, we used a non-parametric test. The Kruskal-Wallis Rank Sum Test was chosen to determine whether there are differences between groups, in this case the retention values recorded for each of the three ecoroof plots. To investigate noted trends further, a Dunn's Test of Multiple Comparisons was applied post hoc to identify groups contributing to model significance.

To visualize the potential differences in $\mathrm{RRC}$ of the roofs by season, the data were divided into wet season and dry season following the categorization specified by Chen and Chang (2019), with the wet season subdivided further into beginning (October-November), middle (December-February), and end (MarchMay) of season. A box-and-whisker plot was created to compare the distribution of RRC values among the different plots between seasons.

\subsubsection{Retention by depth and intensity}

The relationship between event-level RRC and storm intensity was analyzed for the entire study period using multiple statistical approaches. Initially, a direct correlation between intensity and retention was assessed using a 
Spearman's Rank Correlation Coefficient. Additionally, a binary Generalized Linear Regression with a logit link function was used to investigate the relationship between intensity and retention given the logistic distribution of the RRC. From this model, regression coefficients and significance values were determined. Model deviance residuals and fitted values were used to determine goodness-of-fit, and thus the appropriateness of model choice.

\subsubsection{Retention by depth and grouped intensity}

For this portion of the analysis, the conventional rooftop was compared to the $125 \mathrm{~mm}$ section, and the $75 \mathrm{~mm}$ section was compared to the $125 \mathrm{~mm}$ section. The first combination was included as a control measure, and the second combination was to improve the sensitivity of the analysis in regard to significant variance in RRC of the two roof depths, intensity dependent. The intensity of events were divided into three groups, notated as low $\left(0.31 \mathrm{~mm} \mathrm{hr}{ }^{-1}-1.09 \mathrm{~mm}\right.$ $\left.\mathrm{hr}^{-1}\right)$, medium (1.10 $\left.\mathrm{mm} \mathrm{hr}^{-1}-2.11 \mathrm{~mm} \mathrm{hr}^{-1}\right)$, and high $\left(2.12 \mathrm{~mm} \mathrm{hr}^{-1}-4.06 \mathrm{~mm}\right.$ $\mathrm{hr}^{-1}$ ) intensity, with 104, 63, and 14 observations returned, respectively (See Appendix). This was accomplished using a Jenks natural breaks function, as equal breaks might not capture behavior under the types of high intensity events that could result in stormwater concerns. As extreme events often occur much less frequently than smaller events, the higher intensity events should not be equally represented in number of observations within this real-world data set, so this approach assists win maximizing the variance between intensity categories Additionally, using a certain threshold value to define high intensity events is 
difficult under these circumstances, as the limited presence of these events over the three year period would make a statistical analysis unreliable. For example, behavior during the 10-year design storm criteria of $8.64 \mathrm{~mm}$ over a 24 hour period used to determine requirements of other types of SGI (BES 2016) cannot be adequately referenced under these circumstances.

To begin investigating the relationship between intensity and depth, a comparison of all test plots, with retention as the response variable and depth and intensity group as the independent variables was performed. This specific combination of variables was used to establish a difference between ecoroofs and conventional rooftop, as well as to determine whether there is a difference between the two ecoroof plot depths and their response to precipitation events of different intensities. A binary generalized linear model with a logit link was chosen for section of the analysis, with attention paid to the potential interaction between the two grouping variables included. The results of the GLM were then input to a two-way type III ANOVA using the car (Fox et al. 2019) package in R, capable of accepting the GLM model format. If a significant interaction between depth and grouped intensity was observed, the final GLM included this interaction and both grouping variables. If there was no interaction as determined by the ANOVA results, the final linear regression only included significant variables. The deviance of residuals and fitted values were again inspected using qqplots and other methods, to visually confirm a good model fit.

To determine the response of individual plots to precipitation intensity groups, a Kruskal-Wallis Rank Sum Test was run for the retention values of the 
Omm and 125mm ecoroof sections. A Dunn's Test of Multiple Comparisons was performed on the model to derive additional information. 


\section{Results \& Discussion}

\subsection{Annual Rainfall Runoff Capacity}

There were a total of 181 individual storm events (Table 3 ) determined for the three year period. They varied in duration, with longer events spanning multiple days, and shorter events just few hours. This provides a range of precipitation scenarios under which to determine the annual retention capabilities of the roof sections. The conventional roof exhibited an average RRC of $23 \%$ (Table 4), which is comparable to the $19 \%$ retention observed for non-greened roofs in Brussels by Mentens et al. (2006). These authors hypothesized that the retention provided by the non-vegetated rooftop could result from permeability of materials used, as well as depression storage. The $75 \mathrm{~mm}$ rooftop showed an annual RRC of $40 \%$, and the $125 \mathrm{~mm}$ rooftop an annual retention of $31 \%$. The highest rainfall retention was observed for the $75 \mathrm{~mm}$ rooftop for the $2014-2015$ water year, at $56 \%$.

Mean annual rainfall retention volume of an ecoroof plot calculated in this study was $134,028.17$ gallons $\left(507.35 \mathrm{~m}^{3}\right)$, with a total volume reduction of 804,131 gallons $\left(3043.97 \mathrm{~m}^{3}\right)$ for both plots over the entire study period. These volumes could greatly reduce the stormwater load entering the greywater system at that location, and given the relative percentages of RRC noted above, could be considered appropriately representative of an ecoroof of this size in this climate. Even with the rainfall volume reduction of the conventional control plot 
considered, an ecoroof plot still managed to reduce rainfall runoff by an additional $44,998.50$ gallons annually.

Table 3: Event characteristics by water year

\begin{tabular}{lllll}
\hline Water year & Total ppt $(\mathbf{m m})$ & $\mathbf{n}$ events & $\begin{array}{l}\text { Max event } \\
\text { length }(\mathbf{h r})\end{array}$ & $\begin{array}{l}\text { Max event } \\
\text { intensity } \\
\left.\text { (mm } \mathbf{~ h}^{-1}\right)\end{array}$ \\
$\mathbf{2 0 1 4 - 2 0 1 5}$ & 861.57 & 54 & 52 & 4.06 \\
$\mathbf{2 0 1 5 - 2 0 1 6}$ & 1143.00 & 67 & 62 & 2.79 \\
$\mathbf{2 0 1 6 - 2 0 1 7}$ & 1478.78 & 60 & 77 & 2.90 \\
\hline
\end{tabular}

Table 4: Total annual volumetric rainfall retention ratio for each roof depth, calculated using the annual sum total of $P$ and annual sum total $Q$ for each plot. Total runoff volume reduction (gallons) for each section is listed on the bottom row.

\begin{tabular}{|c|c|c|c|c|c|c|c|}
\hline \multirow{2}{*}{$\begin{array}{l}\text { Water } \\
\text { year }\end{array}$} & \multicolumn{2}{|c|}{$0 \mathrm{~mm}$} & \multicolumn{2}{|c|}{$75 \mathrm{~mm}$} & \multicolumn{2}{|c|}{$125 \mathrm{~mm}$} & \multirow{2}{*}{$\begin{array}{l}\text { Eco- } \\
\text { roof } \\
\text { Mean }\end{array}$} \\
\hline & $\begin{array}{l}\text { Retention } \\
(\%)\end{array}$ & $\begin{array}{l}\text { Volume } \\
\text { (gal) }\end{array}$ & $\begin{array}{l}\text { Retention } \\
(\%)\end{array}$ & $\begin{array}{l}\text { Volume } \\
\text { (gal) }\end{array}$ & $\begin{array}{l}\text { Retention } \\
(\%)\end{array}$ & $\begin{array}{l}\begin{array}{l}\text { Volume } \\
\text { (gal) }\end{array} \\
\text { (a) }\end{array}$ & \\
\hline $\begin{array}{l}2014- \\
2015\end{array}$ & 32 & 105460 & 56 & 188620 & 41 & 135401 & 48 \\
\hline $\begin{array}{l}2015- \\
2016\end{array}$ & 15 & 53336 & 41 & 148662 & 25 & 91478 & 33 \\
\hline $\begin{array}{l}2016- \\
2017\end{array}$ & 23 & 108293 & 24 & 111130 & 27 & 128878 & 26 \\
\hline $\begin{array}{l}\text { Total } \\
\text { (gal) }\end{array}$ & & 267088 & & 448372 & & 355759 & \\
\hline
\end{tabular}

Interestingly, this year also saw the lowest amount of precipitation, at only $75 \%$ of the next highest year. These values are well-aligned with, albeit slightly improved, over the $25 \%$ retention observed over a three year period of 
monitoring another Portland, OR ecoroof (Spolek 2008), which implies that a long-term temporal dependent performance study should be considered.

\subsection{Retention by depth}

There is a significant relationship between the depth of ecoroof plot and the retention performance as indicated by the Kruskal-Wallis rank sum test ( $p$ value $=0.00$ ). Further analysis indicates that this significance is observed between the $0 \mathrm{~mm}$ conventional rooftop and the $75 \mathrm{~mm}$ and the $0 \mathrm{~mm}$ and $125 \mathrm{~mm}$ ecoroof plots over the three year period. Although the $75 \mathrm{~mm}$ ecoroof exhibited higher rainfall retention than the $125 \mathrm{~mm}$ ecoroof for two years of the three year study period, there is no significant difference observed between the two ecoroof plots (Table 5). The differences between the ecoroof plots and the conventional rooftop, serving as a control, were anticipated given the potential RRC performance of ecoroofs documented within literature (Table 1). However, the absence of observable difference in RRC behavior between the two ecoroof plots, despite their variation in substrate depth, was more surprising. This finding could serve as particularly influential in regard to local planning, as the structural load requirements of an ecoroof can vary greatly with substrate depth, with requirements ranging from $100 \mathrm{~kg} / \mathrm{m}^{2}$ to $3200 \mathrm{~kg} / \mathrm{m}^{2}$ by increasing depth of a saturated sandy loam soil by $150 \mathrm{~cm}$ (Castiglia Feitosa \& Wilkinson 2016). This implies that there is will be a structural and financial benefit to installing the slightly thinner ecoroof, with weight as a consideration. 
Table 5: Results of statistical tests comparing differences between roof plot depth and rainfall retention capacity $p$-sig $<0.05$

\begin{tabular}{lll}
\hline & Depth & p-value \\
Dunn Test & 0 vs $75 \mathrm{~mm}$ & $0.00^{* *}$ \\
& 0 vs $125 \mathrm{~mm}$ & $0.00^{* *}$ \\
& $75 \mathrm{~mm}$ vs $125 \mathrm{~mm}$ & 0.83 \\
\hline Kruskal-Wallis & chi-squared & 85.34 \\
& p-value & $0.00^{* * *}$ \\
\hline
\end{tabular}

Other studies have observed a difference between ecoroof plot depth and RRC (Feitosa \& Wilkinson 2016, Talebi et al. 2019). Talebi et al. (2019) noted that changes in substrate depth are only impactful on retention capacity if that moisture is actually available for evapotranspiration, otherwise the additional storage of the deeper roof is not available for retention (2019). We hypothesize that this is the driving factor behind the similar performance of ecoroof plots in this study, as it is possible that the deeper ecoroof plot simply takes longer to fully dry out, meaning that the actual available storage volume for both roofs could be similar at storm onset. This is supported by the knowledge that Sedum species are often considered low-water users (Szota et al. 2017), meaning that they will restore substrate storage capacity more slowly than other common ecoroof vegetation options. A study by Li et al. (2018) elucidates the role of root depth and biomass on RRC, indicating that perhaps the observed trend is developing from inaccessible capillary water existing in the deeper portions of the 
substrate after all of the gravitational water has passed through and been registered as discharge, as a result of root structure. It is also possible that this discrepancy could result partially from differences in overall precipitation regime, and therefore intensity of events by frequency, which was not considered in this study. Although there is a 12 hour ADWP, ecoroof discharge can continue well past the precipitation event itself, indicating that there is the possibility that storage capacity has not been fully restored between events

The seasonal and sub-seasonal temporal component appears to impact $\mathrm{RRC}$ of all the three roof sections (Figure 3). This variability in behavior does appear to remain consistent between the $125 \mathrm{~mm}$ and $75 \mathrm{~mm}$ ecoroof plots within each category, based on RRC values. The plot indicates that the greatest RRC for ecoroof plots is observed during the dry season, where $85 \%$ retention accounts for all but outliers for both plots, independently. The opposite is observed for middle wet season, where the median RRC is lowest for the ecoroofs, as well as lower values for the bottom of the lower interquartile range. A Mann-Whitney $U$ Test performed between the $125 \mathrm{~mm}$ retention observations for wet season $(n=139)$ and dry season $(n=23)$ exhibits a highly significant difference $(p=0.00)$ between the hourly retention values of the two seasons. 


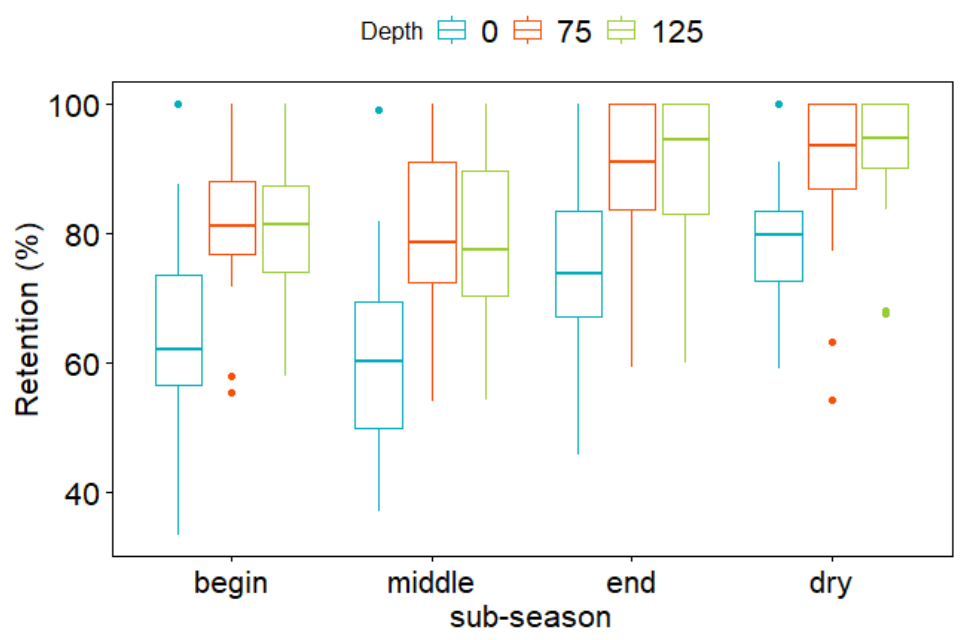

Figure 3: Boxplot exhibiting the RRC of the three roof plots, divided by dry season $(n=23)$ and beginning $(n=31)$, middle $(n=61)$, and end $(n=47)$ of wet season. Depth in $\mathrm{mm}$.

\subsection{Retention by intensity and depth}

Results of the effects of intensity and ecoroof plot presence and depth

were not surprising. Overall, a negative Spearman correlation is observed

between intensity and retention for the control roof $(p=0.03$, rho $=-0.17)$ as well as the $125 \mathrm{~mm}$ roof $(p=0.00$, rho $=-0.37)$. The relationship between intensity and retention shows a negative correlation within the range of observed storm events (Figure 4). Results from the GLM (Table 6) reveal that there is a lower likelihood that the ecoroof plots will experience a $100 \%$ RRC event compared to the conventional roof, when intensity is considered. All independent variables except for continuous intensity display significance within this model. 


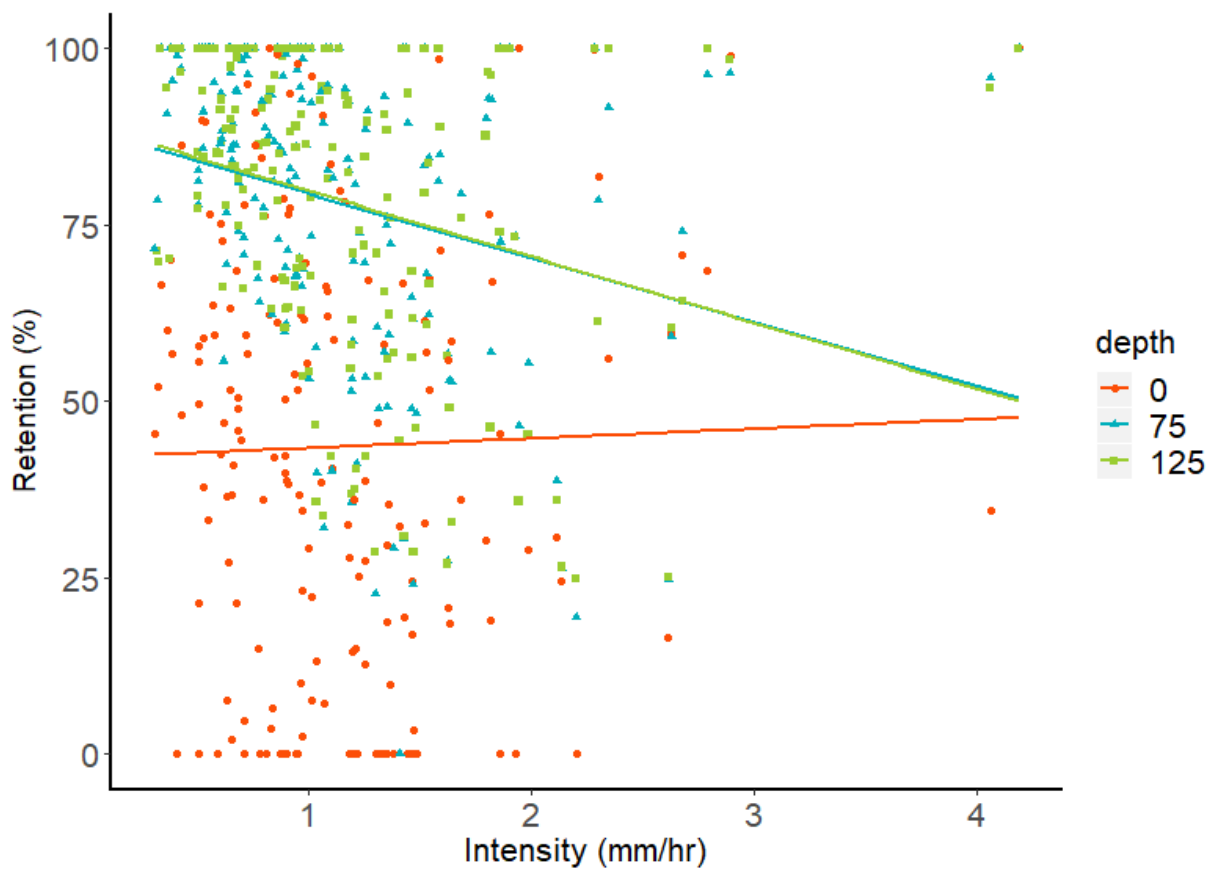

Figure 4: Linear trends associated with event-level retention as a function of intensity, by plot depth. Depth in $\mathrm{mm}$.

As shown in Figure 5 the means of the high intensity $0 \mathrm{~mm}$ and $125 \mathrm{~mm}$ $\mathrm{RRC}$ are quite similar. However, the range of $\mathrm{RRC}$ values is visibly broader for the ecoroof. The reasons for this require further investigation, as this could indicate an unknown factor. Viewing the RRC of both the $75 \mathrm{~mm}$ and $125 \mathrm{~mm}$ roofs, it is obvious that this wide range of RRC values, with some storms exhibiting $>90 \%$ retention, is consistent for both plots. Viewing the data in this format, it appears as though the RRC of the ecoroofs is greatest for the low intensity events, which is expected due to the available storage capacity of the substrate after a 12 hour ADWP, and the volume of water which can be held during these shorter duration or lower volume events. 
Table 6: Generalized linear regression model results, depth vs continuous intensity, all roof plots. $p$-sig $<0.05$. AIC $=$ Akaike information criterion

\begin{tabular}{lll}
\hline GLM & Coefficient (logit) & p-value \\
\hline Intercept & -1.10 & $0.00^{* * *}$ \\
Intensity & 0.74 & $0.05^{* *}$ \\
Depth 75mm & 1.33 & $0.00^{* *}$ \\
Depth $125 \mathrm{~mm}$ & 1.43 & $0.00^{* *}$ \\
Intensity x 75mm & -1.88 & $0.00^{* *}$ \\
Intensity x 125mm & -1.91 & $0.00^{* *}$ \\
\hline AIC & 610.94 & \\
\hline
\end{tabular}

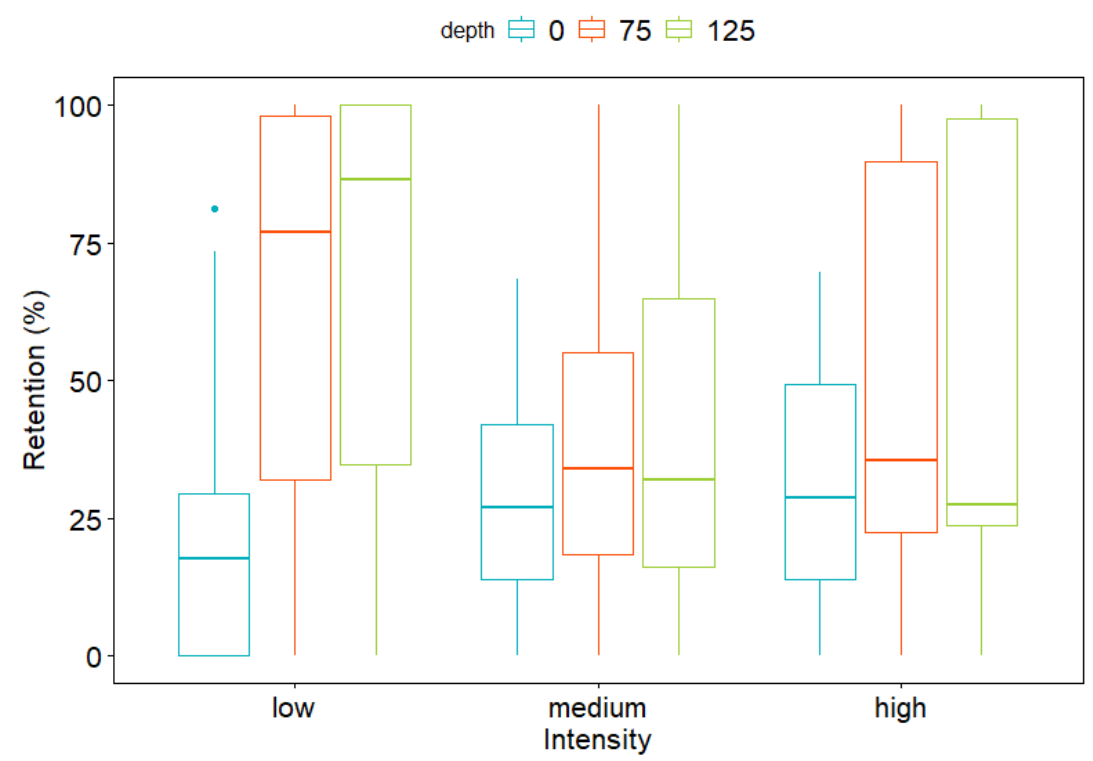

Figure 5: Boxplot exhibiting intensity by group, comparing all three plots. Depth in $\mathrm{mm}$ ( $\mathrm{n}=104$ low, $\mathrm{n}=63$ med, $\mathrm{n}=14$ high).

Neither grouped storm intensity nor plot depth has a direct significant influence on the RRC of the $0 \mathrm{~mm}$ and $125 \mathrm{~mm}$ roofs, with interaction between depth and intensity considered (Table 7). However, the highly significant 24 
interaction between the two grouping variables $(p=0.00)$ indicates that there is likely a joint influence, and thus more investigation is necessary. This is not the case when comparing the $75 \mathrm{~mm}$ and $125 \mathrm{~mm}$ plot sections, where there is a clear relationship between intensity group and RRC, but no difference by depth. These results are consistent with the findings that there is no significant difference between the overall RRC of the $75 \mathrm{~mm}$ and $125 \mathrm{~mm}$ plots, and we can now conclude that this is true under all intensity scenarios. This test, however, does not indicate under which grouped intensity scenarios the significant differences in RRC are observed.

Table 7: ANOVA results for models investigating the relationship between depth and intensity group on roof retention. $p$-sig $<0.05$

\begin{tabular}{lll}
\hline ANOVA & $\mathbf{0 m m} \& \mathbf{1 2 5 m m}$ & $\mathbf{7 5 m m ~ \& ~ 1 2 5 m m ~}$ \\
\hline & $\mathrm{p}$-value & $\mathrm{p}$-value \\
\hline Depth & 0.46 & 0.68 \\
Intensity group & 0.36 & $0.00^{* * *}$ \\
Depth : group & $0.003^{* *}$ & - \\
\hline
\end{tabular}

The $125 \mathrm{~mm}$ section was analyzed (Table 7 ) to determine under which intensity scenarios difference in $\mathrm{RRC}$ are occurring (Table 8). The results indicate that there is a highly significant difference $(p=0.00)$ observed between the RRC of the ecoroof plot during high intensity and low intensity storms. For the conventional control plot, a significant difference is observed between the retention of low versus medium intensity events, but not between low and high intensity events (Table 8), illustrating another difference between conventional 
and ecoroof plots. Although RRC might be decreasing for medium vs low intensity events, the difference is not enough to be highly significant $(p=0.08)$. This could be attributed to the ecoroof's capability of retaining a greater proportion of input from both the low and medium intensity storms, with a progressive decline in ability as the intensity values increase past a certain range. This likely results from a combination of saturated soil and immediate surface runoff, as there is evidence that ecoroof substrate can exhibit greater hydraulic conductivity under certain circumstances (Castiglia Feitosa \& Wilkinson 2016). Once the input volume has surpassed a certain maximum storage capacity, it might be assumed that all additional input would be lost to saturation overland flow.

Table 8: Results of tests comparing differences between retention by grouped intensity. p-sig $<0.05$

\begin{tabular}{llll}
\hline & & conventional & $\mathbf{1 2 5 \mathrm { mm }}$ \\
\hline Dunn Test & Intensity & p-value & $\mathrm{p}$-value \\
& low-med & $0.01^{* *}$ & 0.08 \\
& med-high & $0.93^{*}$ & 0.64 \\
\multirow{2}{*}{ Kruskal-Wallis } & low-high & 0.19 & $0.00^{* * *}$ \\
& chi-squared & $10.10^{* *}$ & $21.59^{* *}$ \\
& p-value & $0.01^{* *}$ & $0.00^{* * *}$ \\
\hline
\end{tabular}

The overall indication of these findings is that the $75 \mathrm{~mm}$ and $125 \mathrm{~mm}$ ecoroof sections are both capable of managing a wide range of precipitation events. However, they might not be adequate for handling the highest intensity 
events, which means that a combination of stormwater green infrastructure types and grey infrastructure (Zhang et al. 2018) might be a better approach to controlling stormwater during periods of higher flood risk. Further comparative analysis between the two ecoroofs under even higher intensity events, or even a comparison of behavior under events containing shorter-duration but higher peak intensity, could elicit any additional underlying variations in behavior. Additionally, comparisons of events matching local return period values (See Appendix) could provide more insight into future performance scenarios.

A thorough analysis of the mechanisms by which the $75 \mathrm{~mm}$ and $125 \mathrm{~mm}$ ecoroof plots are functioning so similarly when controlling rainfall should also be conducted. Measurements of organic material in the substrate, root structure, and below-ground biomass could assist in determining potential sources of influence for this observed behavior. Changes in RRC over time should also be assessed, as functional aspects of the design could shift. 


\section{Conclusions}

The results of this study imply that both $75 \mathrm{~mm}$ and $125 \mathrm{~mm}$ ecoroofs will provide an equivalent level of functionality in regard to controlling stormwater runoff in Portland, OR. Both ecoroofs offer a significant annual improvement over the conventional rooftop spanning the three-year period, providing an average of $40.4 \%$ rainfall retention capacity for the $75 \mathrm{~mm}$ plot and $31.1 \%$ for the $125 \mathrm{~mm}$ plot. When comparing the two ecoroof's performance under precipitation events of varying intensities, it is observed that performance is significantly improved under low intensity events as opposed to high intensity events. Overall, there is a negative relationship between precipitation intensity and RRC.

These findings are applicable to local planning, as they inform decisionmakers of the minimum specifications necessary to meet specific performance requirements. It can be assumed that, since the two ecoroof plots exhibit similar performance, the shallower depth would be a preferable planning option, as it requires less materials and results in less of a weight burden on the associated structure. This study could benefit from a further analysis looking at the realworld functionality of an ecoroof in this region over a longer time period, to capture more of the larger-scale precipitation events. Knowledge would also be benefited by a local study with a focus on assessment of long-term temporal shifts in ecoroof RRC in order to detect potential changes in the roof's capacity to manage incoming precipitation. 


\section{Citations}

Akther, Musa, Jianxun He, Angus Chu, Jian Huang, and Bert van Duin. A Review of Green Roof Applications for Managing Urban Stormwater in Different Climatic Zones. 2018. Sustainability. 10, 2864.

Berto, Raul, Carlo Antonio Stival, and Paolo Rosato. 2018. Enhancing the Environmental Performance of Industrial Settlements: An Economic Evaluation of Extensive Green Roof Competitiveness. Building and Environment 127: 58-68. https://doi.org/10.1016/j.buildenv.2017.10.032

BES. n.d. Ecoroof Incentive. City of Portland. Web. Accessed June 2018. https://www.portlandoregon.gov/bes/article/547491

BES. 2007. Sewer and Drainage Facilities Design Manual. Web. Accessed May 2019. https://www.portlandoregon.gov/bes/article/360710

BES. 2009. Ecoroof Floor Area Ratio Bonus Option. Web. Accessed May 2019. https://www.portlandoregon.gov/bes/article/474490

BES. 2010. Portland Ecosystem Guide. City of Portland. Web. Accessed June 2018. https://www.portlandoregon.gov/bes/article/331490

BES. 2016. City of Portland Stormwater Management Manual. City of Portland. Web. Accessed June 2018. https://www.portlandoregon.gov/bes/64040

Bouzouidja, R, G. Sere, R. Claverie, S. Ouvrard, L. Nuttens, D. Lacroix. 2018. Green roof againg: Quantifying the impact of substrate evolution on hydraulic performances at the lab-scale. Journal of Hydrology. 564: 416-423. https://doi.org/10.1016/j.jhydrol.2018.01.032.

Burszsta-Adamiak, Ewa, J. Stanczyk and J. Lomotowski. 2018. Hydrological perfomrance of green roofs in the context of the meteorological factors during the 5-year monitoring period. Water and Environment Journal. 33:144-154. http://doi.org/10.1111/wej.12385.

Castiglia Feitosa, R., and Sara Wilkingson. 2016. Modelling green roof stormwater response for different soil depths. Landscape and Urban Planning. 153:170-179.

Chen, Junjie and Heejun Chang. 2019. Dynamics of wet-season turbidity in relation to precipitation, discharge, and land cover in three urbanizing watersheds, Oregon. River Research and Applications. 2019: 1-13. DOI: $10.1002 /$ rra.3487.

Cipolla, S.S., Maglionico, M., Stojkov, I., 2016. A long-term hydrological modelling of an extensive green roof by means of SWMM. Ecological Engineering 95, 876-887. https://doi.org/10.1016/i.ecoleng.2016.07.009

Cooley, Alexis and Heejun Chang. 2017. Precipitation Intensity Trend Detection Using Hourly and Daily Observations in Portland, Oregon. Climate 5, no. 1: https://doi.org/10.3390/cli5010010.

De-Ville, Simon, Manoj Menon, and Virginia Stovin. 2018. Temporal Variations in the Potential Hydrological Performance of Extensive Green Roof Systems.Journal of Hydrology 558: 564-78. https://doi.org/10.1016/i.jhydrol.2018.01.055. 
Fox, John and Sanford Weisberg (2019). An $\{R\}$ Companion to Applied Regression, Third Edition. Thousand Oaks CA: Sage.

URL: https://socialsciences.mcmaster.ca/jfox/Books/Companion/

Garrett Grolemund, Hadley Wickham (2011). Dates and Times Made Easy with lubridate. Journal of Statistical Software, 40(3), 1-25. URL http://www.jstatsoft.org/v40/i03/.

Hill, Jenny, Jennifer Drake, Brent Sleep, and Liat Margolis. 2017. Influences of Four Extensive Green Roof Design Variables on Stormwater Hydrology. Journal of Hydrologic Engineering 22, no. 8: 04017019. https://doi.org/10.1061/(ASCE)HE.1943-5584.0001534.

Koffler, Daniel, Tobia Gauster, and Gregor Laaha. 2016. Calculation of low flow statistics for daily stream flow data. R-package version 0.9.4. https://CRAN.R-project.org/package=lfstat

Liu, Chunlu, Yan Li and Jun Li. 2017. Geographic information system-based assessment of mitigating flash-flood disaster from green roof systems. Computers, Environment and Urban Systems. 64: 321-331. https://doi.org/10.1016/i.compenvurbsys.2017.04.008.

Liu, Wen, Qi Feng, Weiping Chen, Wei Wei and Ravinesh Deo. 2019. The influence of structural factors on stormwater runoff retention of extensive green roofs: new evidence from scale-based models and real experiments. Journal of Hydrology. 569:230-238. https://doi.org/10.1016/i.hydrol.2018/11.066.

Michelson, K., and Chang, H. (2019) Spatial Characteristics and Frequency of Citizen-Observed Pluvial Flooding Events in Relation to Storm Size in Portland, Oregon, Urban Climate

McPhillips, Lauren E., and A. Marissa Matsler. 2018. Temporal Evolution of Green Stormwater Infrastructure Strategies in Three US Cities. Frontiers in Built Environment 4. https://doi.org/10.3389/fbuil.2018.00026.

Mentens, Jeroen, Dirk Raes, and Martin Hermy. 2006. Green Roofs as a Tool for Solving the Rainwater Runoff Problem in the Urbanized 21st Century? Landscape and Urban Planning 77, no. 3: 217-26. https://doi.org/10.1016/i.landurbplan.2005.02.010.

Nardini, Andrea, Sergio Andri, and Maurizio Crasso. 2012. Influence of substrate depth and vegetation type on temperature and water runoff mitigation by extensive green roofs: shrubs versus herbaceous plants. Urban Ecosystems. 15:697-708.

Oregon Metro. 2016. Portland region nears 2.4 million residents, growing by 41,000 last year. Web. Accessed June, 2018.https://www.oregonmetro.gov/news/portland-region-nears-24million-residents-growing-41000-last-year

Palla, Anna, Ilaria Gnecco, and Luca Lanza. 2010. Hydrologic Restoration in the Urban Environment Using Green Roofs. Water 2, no. 2: 140-54. https://doi.org/10.3390/w2020140.

Quickfacts. Portland City, OR. US Census Bureau. Web. Accessed June 2019. https://www.census.gov/quickfacts/portlandcityoregon 
Redfern, Thomas W., Neil Macdonald, Thomas R. Kjeldsen, James D. Miller, and Nick Reynard. 2016. Current Understanding of Hydrological Processes on Common Urban Surfaces. Progress in Physical Geography 40, no. 5: 699-713. https://doi.org/10.1177/0309133316652819.

Rosenzweig, B., McPhillips, L., Chang, H., Cheng, C., Welty, C., Matsler, M., Iwaniec, D. (2018) Urban pluvian flood risk and opportunities for resilience, Wires Water DOI: 10.1002/wat2.1302

Rupp, D, J. Abatzoglou, P. Mote. 2017. Projections of $21^{\text {st }}$ century climate of the Columbia River Basin. Climate Dynamics. 49:1783-1799.fo

Schultz, Isaac, David J. Sailor, and Olyssa Starry. 2018. Effects of Substrate Depth and Precipitation Characteristics on Stormwater Retention by Two Green Roofs in Portland OR. Journal of Hydrology: Regional Studies 18: 110-18. https://doi.org/10.1016/i.ejrh.2018.06.008.

Shafique, Muhammad, Reeho Kim, and Kwon Kyung-Ho. 2018. Green Roof for Stormwater Management in a Highly Urbanized Area: The Case of Seoul, Korea. Sustainability 10, no. 3: 584. https://doi.org/10.3390/su10030584.

Soulis, Konstantinos X., Nikolaos Ntoulas, Panayiotis A. Nektarios, and George Kargas. 2017. Runoff Reduction from Extensive Green Roofs Having Different Substrate Depth and Plant Cover. Ecological Engineering 102: 80-89. https://doi.org/10.1016/j.ecoleng.2017.01.031.

Spolek, Graig. 2008. Performance Monitoring of Three Ecoroofs in Portland, Oregon. Urban Ecosystems 11, no. 4: 349-59. https://doi.org/10.1007/s11252-008-0061-z.

Starry, Olyssa, John Lea-Cox, Andrew Ristvey, and Steven Cohan. 2016. Parameterizing a Water-Balance Model for Predicting Stormwater Runoff from Green Roofs. Journal of Hydrologic Engineering 21, no. 12: 04016046. https://doi.org/10.1061/(ASCE)HE.1943-5584.0001443.

Stovin, Virginia, Simon Poë, and Christian Berretta. 2013. A Modelling Study of Long Term Green Roof Retention Performance. Journal of Environmental Management 131: 206-15. https://doi.org/10.1016/j.jenvman.2013.09.026.

Stovin, Virginia, Gianni Vesuviano, and Simon De-Ville. 2017. Defining Green Roof Detention Performance. Urban Water Journal 14, no. 6: 574-88. https://doi.org/10.1080/1573062X.2015.1049279.

Szota, Christopher, Claire Farrel, Nicholas Williams, Stefan Arndt, Tim Fletcher. 2017. Drought-avoiding plants with low water use can achieve high rainfall retention without jeopardising survival on green roofs. Science of the total Environment. 603-604:340-351.

Talebi, Ashkan, Scott Bagg, Brent Sleep, Denis O'Carroll. 2019. Water retention performance of green roof technology: A comparison of canadian climates. Ecological Engineering. 126:1-15.

U.S. climate data. Climate Portland-Oregon. Web. Accessed June 2019. www.usclimatedata.com 
USGS. 2018. HYDRA Rainfall Network. https://or.water.usgs.gov/nonusgs/bes/raingage info/clickmap.html

Viola, F, M. Hellies, and R. Deidda. 2017. Retention performance of green roofs in representative climates worldwide. Journal of Hydrology. 553:763-772.

Voyde, E., Fassman, E., and Simcock, R., 2010. Hydrology of an extensive living roof under sub-tropical climate conditions in Auckland. New Zealand. Journal of Hydrology, 394 (3 - 4), 384- 395.

Wickham, Hadley, Romain Francois, Lionel Henry and Kirill Muller. 2018. dplyr: A grammar of data manipulation. $R$ package version 0.7.6. https://CRAN.R-project.org/package=dplyr

Zhang, Kun, and Ting Fong May Chui. 2018. A Comprehensive Review of Spatial Allocation of LID-BMP-GI Practices: Strategies and Optimization Tools. Science of The Total Environment 621: 915-29. https://doi.org/10.1016/j.scitotenv.2017.11.281.

Zhang, Shouhong, and Yiping Guo. 2013. Analytical Probabilistic Model for Evaluating the Hydrologic Performance of Green Roofs. Journal of Hydrologic Engineering 18, no. 1: 19-28. https://doi.org/10.1061/(ASCE)HE.1943-5584.0000593. 


\section{Appendix: Supplemental Analysis}

Table 9: Frequency of events within each precipitation intensity group, by year

\begin{tabular}{llll}
\hline & Iow & medium & high \\
$\mathbf{2 0 1 4 - 2 0 1 5}$ & $64.6 \%$ & $29.2 \%$ & $6.3 \%$ \\
$\mathbf{2 0 1 5 - 2 0 1 6}$ & $60.0 \%$ & $33.8 \%$ & $6.2 \%$ \\
$\mathbf{2 0 1 6 - 2 0 1 7}$ & $54.2 \%$ & $37.3 \%$ & $8.5 \%$ \\
\hline
\end{tabular}



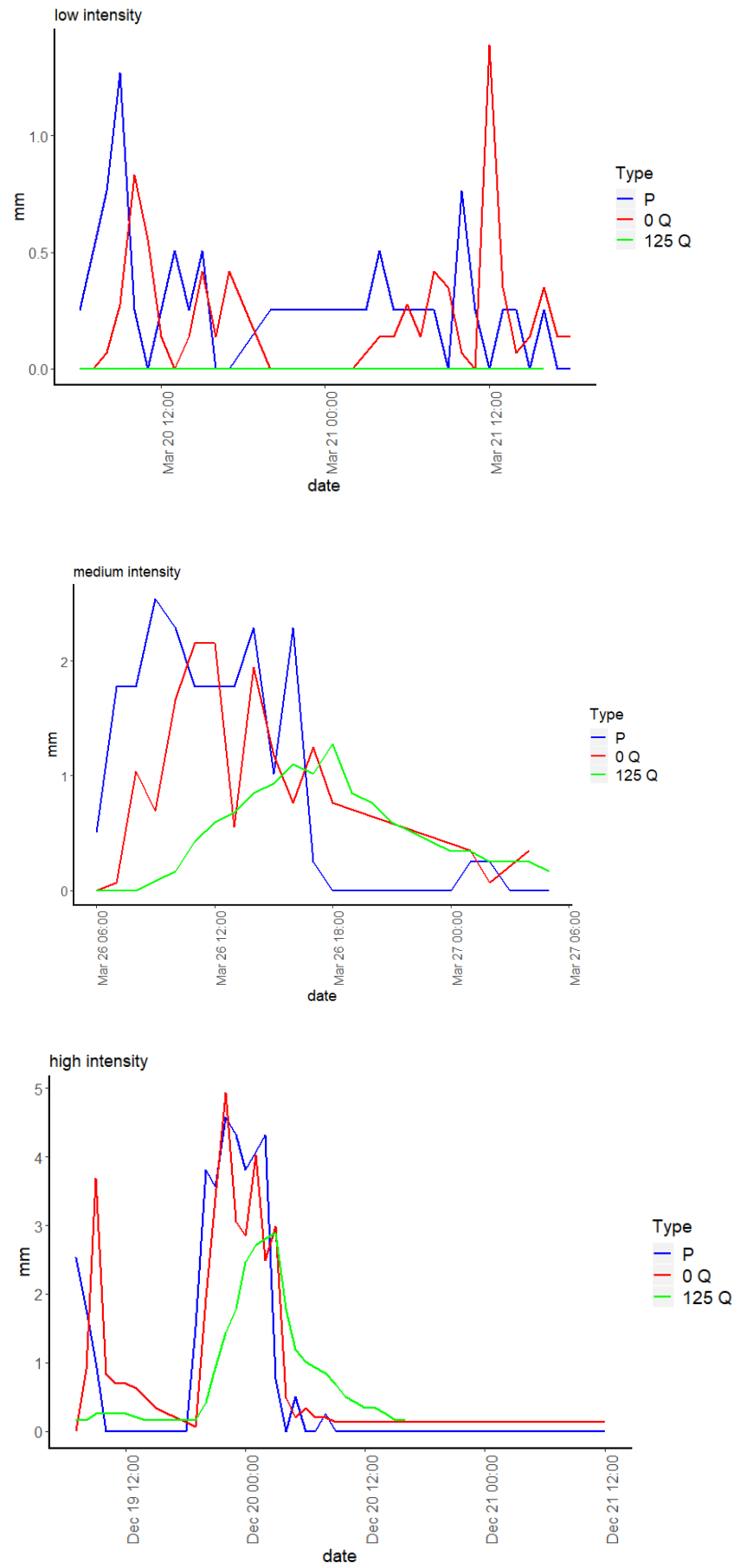

Figure 6: Individual high, medium, and low intensity storm behavior for the $125 \mathrm{~mm}$ and conventional roof sections. Peak hourly intensity is $4.572 \mathrm{~mm} \mathrm{hr}^{-1}, 2.54 \mathrm{~mm} \mathrm{hr}^{-}$ $1,1.27 \mathrm{~mm} \mathrm{hr}^{-1}$, respectively. All peak values fall within a one year design-storm recurrence interval for the Portland area (BES 2007). 